\title{
Severe hypophosphatemia induced after first cycle of the ESHAP protocol for Hodgkin's lymphoma:
}

\section{a case report}

\author{
Shereen Elazzazy' \\ Hager A El-Geed ${ }^{2}$ \\ Sumaya AI Yafei ${ }^{1}$ \\ 'Pharmacy Department, National \\ Center for Cancer Care and \\ Research, Hamad Medical \\ Corporation, ${ }^{2}$ College of Pharmacy, \\ Qatar University, Doha, Qatar
}

This article was published in the following Dove Press journal:

International Medical Case Reports Journal

3 January 2013

Number of times this article has been viewed

\begin{abstract}
The effect of the ESHAP (etoposide, methylprednisolone, cytarabine, cisplatin) salvage protocol on serum electrolytes has been previously reported by individual observational studies. The most commonly described electrolyte affected by the ESHAP protocol is magnesium. In addition, hypophosphatemia has been studied and reported as a complication of cisplatin therapy, although it is usually asymptomatic. This is a case report of a 51-year-old woman with relapsed Hodgkin's lymphoma who developed severe hypophosphatemia following administration of the first cycle of the ESHAP protocol. The patient started to develop gradually decreasing phosphate levels 2 weeks after receiving chemotherapy, which needed to be corrected by phosphate supplementation. This case report raises concern regarding hypophosphatemia as a possible side effect of the ESHAP protocol and points to a need for close monitoring, taking into consideration vitamin D levels, urinary phosphate excretion, parathyroid hormone levels, and arterial blood gas analysis to rule out other contributing factors. Health care providers should be made aware of this possible toxicity. Critical monitoring of phosphate levels and considering supplementation is warranted with the ESHAP protocol, especially when it is used in combination with granulocyte colony-stimulating factor and diuretics, to prevent such possible hypophosphatemia. Further investigations may be required to confirm and evaluate the significance of this type of toxicity.
\end{abstract}

Keywords: hypophosphatemia, ESHAP, salvage protocol, relapsed Hodgkin's lymphoma

\section{Introduction}

Several conditions are known to induce moderate to severe hypophosphatemia. They include low dietary intake, conditions associated with decreased absorption or increased urinary phosphate excretion, and conditions associated with shifts in phosphate from the extracellular to intracellular fluid. The latter include various cellular uptake syndromes, in which hypophosphatemia develops as a result of phosphate consumption by rapidly proliferating cells. ${ }^{1,2}$ The association between hypophosphatemia and cytokines has recently been investigated, and some authors have reported that hypophosphatemia can be induced directly by certain cytokines. ${ }^{3,4}$

The ESHAP (etoposide, methylprednisolone, cytarabine, and cisplatin) protocol is an effective treatment for Hodgkin's lymphoma, ${ }^{5,6}$ and the effect of this protocol on serum electrolytes has been reported previously in some individual observational studies. The most commonly described electrolyte affected is magnesium. Other electrolyte imbalances are seen mainly in patients receiving cisplatin. In a study published in 2012, there was a significant decrease in serum electrolytes including magnesium, potassium, phosphorus, and calcium, following use of this agent. ${ }^{7}$

Correspondence: Shereen Elazzazy Pharmacy Department, National Center for Cancer Care and Research, Hamad Medical Corporation, Doha, Qatar Tel +9745500 962I

Email shereen_amin@yahoo.com
International Medical Case Reports Journal 2013:6 I-5

(C) 2013 Elazzazy et al, publisher and licensee Dove Medical Press Ltd. This is an Open Access article which permits unrestricted noncommercial use, provided the original work is properly cited.
Dovepress

http://dx.doi.org// 0.2147/IMCRJ.S37286 
Hypophosphatemia induced by ESHAP is not well described, and is rarely considered as a side effect of the chemotherapeutic agents in this protocol. Herein, we report a case of severe hypophosphatemia concomitant with administration of the first cycle of the ESHAP protocol to a patient with Hodgkin's lymphoma.

\section{Case report}

A 51-year-old woman (weight $55 \mathrm{~kg}$, height $160 \mathrm{~cm}$ ) with a history of hypertension, hepatitis $\mathrm{C}$ infection, chronic liver disease with ascites, esophageal varices, and mild renal impairment, was admitted electively to the National Centre for Cancer Care and Research, Doha, Qatar, on April 22, 2012 to receive her first cycle of salvage ESHAP protocol for treatment of recently relapsed Hodgkin's lymphoma.

Her medications consisted of entecavir $1 \mathrm{mg}$ once daily, propranolol $20 \mathrm{mg}$ twice daily, spironolactone $50 \mathrm{mg}$ once daily, allopurinol $100 \mathrm{mg}$ once daily, furosemide $40 \mathrm{mg}$ once daily, and lactulose $30 \mathrm{~mL}$ twice daily.

On April 23, 2012 she was started on the first dose of cycle 1 of the intravenous ESHAP protocol as follows: etoposide $40 \mathrm{mg} / \mathrm{m}^{2} /$ day on days $1-4$; methylprednisolone $500 \mathrm{mg}$ /day on days $1-4$; cytarabine $2000 \mathrm{mg} / \mathrm{m}^{2}$ on day 5 ; and cisplatin $25 \mathrm{mg} / \mathrm{m}^{2} /$ day as a continuous infusion on days $1-4$. She finished her first cycle on April 27, 2012. Her laboratory values prior to, throughout, and 24 hours after finishing this cycle of chemotherapy were essentially normal (Table 1), and she was discharged home on April 28, 2012 (day 6 of chemotherapy).

Two days later (day 8 of chemotherapy) she was readmitted with a temperature of $38.9^{\circ} \mathrm{C}$. At this time she had a normal complete blood count and electrolyte levels (Table 1), and was started empirically on intravenous vancomycin $1 \mathrm{~g}$ every 12 hours and piperacillin-tazobactam $4.5 \mathrm{~g}$ every 8 hours. On day 10 ( 5 days after completion of treatment), she developed leukopenia and neutropenia (white cell count $900 / \mu \mathrm{L}$ and absolute neutrophil count $800 / \mu \mathrm{L}$ ), and her phosphorus level was $0.73 \mathrm{mmol} / \mathrm{L}$. She was started on granulocyte colonystimulating factor (filgrastim $300 \mu \mathrm{g}$ subcutaneously once a day for 8 days), at which time her white cell count continued to drop and reached $200 / \mu \mathrm{L}$ on day 13 (8 days after completion of treatment), and then started to recover, as shown in Table 1. The phosphorus level continued to drop, and on day 17 (12 days after completion of treatment) reached a critical level of $0.34 \mathrm{mmol} / \mathrm{L}$ (asymptomatic hypophosphatemia) and potassium dropped to $2.4 \mathrm{mmol} / \mathrm{L}$, although renal function and serum calcium were normal. She was given a $20 \mathrm{mmol}$ intravenous potassium phosphate infusion on two successive days and was started on neutral phosphate $250 \mathrm{mg}$ orally three times daily. Her serum phosphate returned to normal after 4 days, and was maintained at $1.35 \mathrm{mmol} / \mathrm{L}$ after discontinuing supplementation.

\section{Discussion}

This report describes a patient with severe hypophosphatemia after administration of the first cycle of the ESHAP protocol and granulocyte colony-stimulating factor started on day 10 ( 5 days after completion of treatment) to treat the chemotherapy-induced leukopenia and neutropenia. ESHAP is an effective salvage strategy for Hodgkin's lymphoma, and is associated with an overall response rate of approximately $70 \%-80 \%{ }^{8,9}$ The effect of this protocol on serum electrolytes has been reported previously by some individual observational studies, and magnesium has been the electrolyte most commonly mentioned. Further, hypophosphatemia has been reported as a complication of cisplatin therapy, although has been usually asymptomatic. ${ }^{10}$ Being infrequent complications, the exact cause of cisplatin-induced hypophosphatemia and hypobicarbonatemia is not known, but significant hypophosphatemia was observed in $67 \%$ of patients in one study, particularly in female patients. ${ }^{11}$ Another Phase II study examined the effect of fludarabine, cytarabine, cyclophosphamide, cisplatin, and granulocyte macrophage colonystimulating factor in patients with Richter's syndrome and refractory lymphoproliferative disorders, and hypophosphatemia was reported in $10 \%$ of cases. ${ }^{11}$

The association between hypophosphatemia and cytokines has recently been investigated, and some authors have reported that hypophosphatemia can be induced directly by certain cytokines. ${ }^{3,4}$ Cytokines are low molecular weight proteins and glycoproteins that are secreted principally by activated lymphocytes and macrophages, and have a wide range of functions in the hematopoietic and immune systems. It has been postulated that characteristic clinical and histopathological features of malignant lymphomas may be due to activation of cytokines. Cytokine levels decreased after chemotherapy in patients showing a response to therapy. However, there are some conflicting and unreliable trends in interleukin-6 levels after chemotherapy, with persistently elevated levels seen in patients in clinical remission. ${ }^{12}$

Various cytokines are associated with the development of hypophosphatemia. Recent research has evaluated the interrelationship between cytokine release, rise in white cell count, and development of hypophosphatemia. ${ }^{4}$ The median time taken to reach the minimum phosphate level was 8 days. There was a significant correlation between 


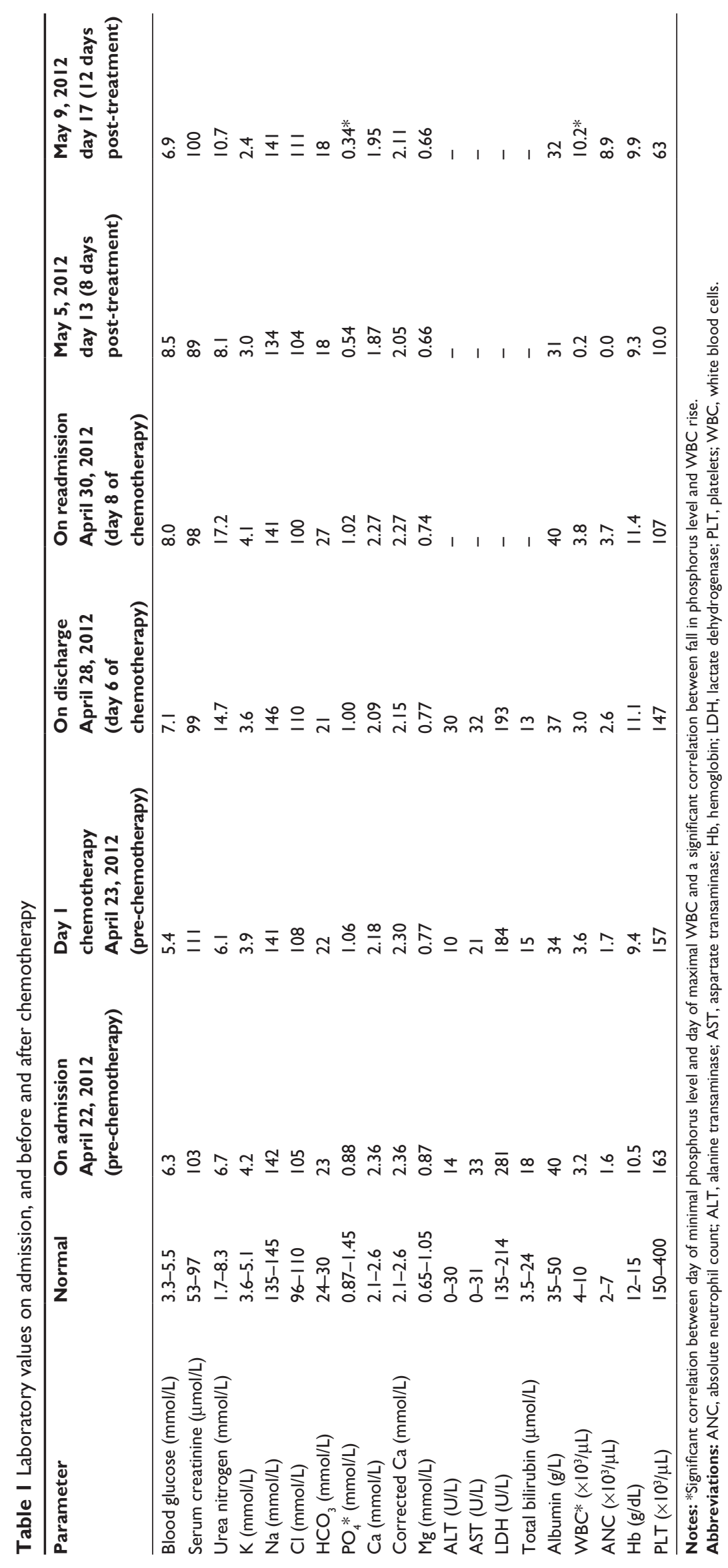


Table 2 Naranjo causality scale for adverse drug reactions ${ }^{13}$

\begin{tabular}{|c|c|c|c|c|}
\hline \multirow[t]{2}{*}{ Question } & \multicolumn{4}{|c|}{ Scoring } \\
\hline & Yes & No & $\begin{array}{l}\text { Do not know } \\
\text { or unavailable }\end{array}$ & Score \\
\hline $\begin{array}{l}\text { I. Are there previous conclusive reports } \\
\text { on this reaction? }\end{array}$ & +1 & 0 & 0 & +1 \\
\hline $\begin{array}{l}\text { 2. Did the adverse event appear after } \\
\text { the suspected drug was given? }\end{array}$ & +2 & +1 & 0 & +2 \\
\hline $\begin{array}{l}\text { 3. Did the adverse reaction improve when } \\
\text { the drug was discontinued or a specific } \\
\text { antagonist was given? }\end{array}$ & +1 & 0 & 0 & +1 \\
\hline $\begin{array}{l}\text { 4. Did the adverse reaction appear when } \\
\text { the drug was readministered? }\end{array}$ & +2 & -1 & 0 & 0 \\
\hline $\begin{array}{l}\text { 5. Are there alternative causes that could } \\
\text { have caused the reaction? }\end{array}$ & -1 & +2 & 0 & +2 \\
\hline $\begin{array}{l}\text { 6. Did the reaction reappear when a placebo } \\
\text { was given? }\end{array}$ & -1 & +1 & 0 & 0 \\
\hline $\begin{array}{l}\text { 7. Was the drug detected in any body fluid } \\
\text { in toxic concentrations? }\end{array}$ & +1 & 0 & 0 & 0 \\
\hline $\begin{array}{l}\text { 8. Was the reaction more severe when the } \\
\text { dose was increased/increasing, or less } \\
\text { severe when the dose was decreased? }\end{array}$ & +1 & 0 & 0 & 0 \\
\hline $\begin{array}{l}\text { 9. Did the patient have a similar reaction to } \\
\text { the same or similar drugs in any } \\
\text { previous exposure? }\end{array}$ & +1 & 0 & 0 & 0 \\
\hline $\begin{array}{l}\text { 10. Was the adverse event confirmed by } \\
\text { any objective evidence? }\end{array}$ & +1 & 0 & 0 & +1 \\
\hline Total & & & & +7 \\
\hline
\end{tabular}

Notes: Scoring: $>9$, definite adverse drug reaction; $5-8$, probable definite adverse drug reaction; I-4, possible definite adverse drug reaction; 0 , doubtful definite adverse drug reaction. ${ }^{13}$

day of the minimum phosphate level and day of maximum white cell count, and a significant correlation between the decrease in phosphate level and the increase in white blood cells. ${ }^{3,4}$ In the present case report, our patient developed asymptomatic hypophosphatemia starting on day 10 (ie, 8 days after receiving chemotherapy and granulocyte colony-stimulating factor, which is known to be associated with release of cytokines and an increase in white cell count) and showed a significant correlation between day of minimum phosphate level and day of maximum white cell count, along with a significant correlation between the decrease in phosphate level and increase in white cell count (Table 1). Cytokine levels were not measured, but the clinical findings in our patient were consistent with previously reported data. Serious manifestations of hypophosphatemia were prevented by phosphate infusion, and recurrence of hypophosphatemia was prevented by oral supplementation, and addressing other factors that might have contributed to development of hypophosphatemia (vitamin D, urinary phosphate excretion, parathyroid hormone, arterial blood gas analysis, or any other drug which might have aggravated the effect of cisplatin).
Using the Naranjo scale for adverse drug reactions, we obtained a score of 7 (probable adverse drug reaction, see Table 2). ${ }^{13}$ Based on this score and our clinical and investigation findings, we considered the possibility of severe hypophosphatemia being induced after the first cycle of the ESHAP protocol. In view of the critical level of hypophosphatemia seen in our patient, close monitoring of phosphate levels and consideration of supplementation is warranted with the ESHAP protocol, especially when it is used in combination with granulocyte colony-stimulating factor and diuretics. This is a novel finding in the sense that, to the authors' knowledge, this side effect has not been reported previously. Health care providers should be aware of this potential toxicity, and appropriate monitoring of patients should be implemented.

\section{Conclusion}

The ESHAP protocol may induce severe hypophosphatemia at a late stage. Patients receiving this protocol should have their serum phosphate levels monitored throughout treatment, because some would require phosphate supplementation in the second and third weeks after chemotherapy, taking 
into consideration the need to evaluate other potentially contributing factors, including concomitant medications, vitamin D levels, urinary phosphate excretion, parathyroid hormone, and arterial blood gas analysis.

\section{Disclosure}

The authors report no conflicts of interests in this work.

\section{References}

1. Betro MG, Pain RW. Hypophosphataemia and hyperphosphataemia in a hospital population. BMJ. 1972;1:273-276.

2. Ra'anani P, Lahav M, Prokocimer M, et al. Life threatening hypophosphataemia in a patient with Philadelphia chromosome-positive chronic myelogenous leukaemia in acute blastic crisis. Postgrad Med J. 1992;68:283-286.

3. MacDonald R. Red cell 2,3-diphosphoglycerate and oxygen affinity. Anaesthesia. 1977;32:544-553.

4. Raanani P, Levi I, Holzman F, et al. Engraftment-associated hypophosphatemia - the role of cytokine release and steep leukocyte rise post stem cell transplantation. Bone Marrow Transplant. 2001;27:311-317.

5. Majumdar G. Severe hypomagnesaemia with tetany following ESHAP protocol. BMC Blood Disord. 2002;2:1.
6. Aparicio J, Segura A, Garcerá S, et al. ESHAP is an Active Regimen for Relapsing Hodgkin's Disease. Ann Oncol. 1999;10(5):593-595.

7. Arunkumar PA, Viswanatha GL, Radheshyam N, Mukund H, Belliyappa MS. Science behind cisplatin-induced nephrotoxicity in humans: a clinical study. Asian Pacific Journal of Tropical Biomedicine. 2012;2:640-644.

8. Aparicio J, Segura A, Garcerá S, et al. ESHAP is an active regimen for relapsing Hodgkin's disease. Ann Oncol. 1999;10:593-595.

9. Velasquez WS, McLaughlin P, Tucker S, et al. ESHAP - an effective chemotherapy regimen in refractory and relapsing lymphoma: a 4-year follow-up study. J Clin Oncol. 1994;12:1169-1176.

10. Liamis G, Milionis H, Elisaf M. Medication-induced hypophosphatemia: a review. $Q J$ Med. 2010;103:449-459.

11. Tsimberidou AM, O'Brien SM, Cortes JE, et al. Phase II study of fludarabine, cytarabine (Ara-C), cyclophosphamide, cisplatin and GM-CSF (FACPGM) in patients with Richter's syndrome or refractory lymphoproliferative disorders. Leuk Lymphoma. 2002;43:767-772.

12. Chopra GS, Chitalkar PG, Jaiprakash MP. Cytokines: as useful prognostic markers in lymphoma cases. Medical Journal Armed Forces India. 2004;60:45-49.

13. Naranjo CA, Busto U, Sellers EM, et al. A method for estimating the probability of adverse drug reactions. Clin Pharmacol Ther. 1981;30: 239-245.

\section{Publish your work in this journal}

The International Medical Case Reports Journal is an international, peer-reviewed open-access journal publishing original case reports from all medical specialties. Previously unpublished medical posters are also accepted relating to any area of clinical or preclinical science. Submissions should not normally exceed 2,000 words or

\section{Dovepress}

4 published pages including figures, diagrams and references. The manuscript management system is completely online and includes a very quick and fair peer-review system, which is all easy to use. Visit http://www.dovepress.com/testimonials.php to read real quotes from published authors.

Submit your manuscript here: http://www.dovepress.com/international-medical-case-reports-journal-journal 